\section{Psychiatric disorders in neurocysticercosis}

SIR: Unfortunately psychiatrists are not aware of the epidemiological relevance of neurocysticercosis (NCC) and its psychiatric problems. The most frequent neuroparasitosis, NCC is the infestation of the central nervous system with larvae of the cestode Taenia solium. Complex neurological, neurosurgical, and psychiatric syndromes result. Endemic in developing countries, including China and India, the world's most populated, NCC is also endemic in groups within the developed countries, especially among the growing number of migrants (the American Hispanics are a good example) and travellers (Richards et al, 1985).

Last century, NCC was observed in up to $2 \%$ of the brains autopsied in Berlin. Hidden NCC may have occurred in patients of the German fathers of psychiatry, since it was so common. Griesinger (1862) produced the first classification of NCC, based upon its psychiatric symptoms. The difficulties for diagnosis during life were formidable. Up until the 1930s, NCC captured much attention of psychiatrists, but not after that, as the interest in neuropsychiatry gradually faded. Until recently, pathological examination of brain tissue was the only means for secure diagnosis. Improvements in immunodiagnosis and neuroimaging (computerised tomography and magnetic resonance imaging) last decade brought to the surface an iceberg of undiagnosed cases.

In endemic regions, NCC is currently part of the differential diagnosis of most neurological disorders, but not of psychiatric. The pathology of NCC include arachnoiditis, infarcts secondary to vasculitis, hydrocephalus secondary to meningeal inflammation and fibrosis, parasitic cysts (parenchymal, intraventricular, and spinal), mass effect of large cysts and fibrocalcified nodules. The clinical manifestations are pleomorphic, depending on number, size, and topography of lesions, inflammatory and immune host responses and sequelae of previous infestations (Sotelo et al, 1985). More severe cases are lifethreatening, neurosurgery is commonly necessary and incapacitating disabilities often result. Soon after the onset patients may be unable to work.

NCC frequently affects life quality and social support. The German psychiatrist Henneberg affirmed that psychiatric problems were never absent in NCC.

In addition to neurobehavioural disorders associated with neurological and neurosurgical problems, pure psychic forms are found in up to $15 \%$ of the NCC patients, which mimic various psychiatric disorders. In England, among 450 soldiers who acquired NCC in service abroad, Dixon et al (1961) reported psychiatric forms in 39 , organic deterioration in 21, affective disorder in 11, schizophrenia in 3, schizoidy in 1, paranoia in 1 and psychoneuroses with hysterical features in 2 .

NCC mimics schizophrenia, and, recently, in Middlesex, a case of NCC was detected among 268 cases of first-episode schizophrenia investigated for medical illnesses (Johnstone et al, 1987). In homes for the elderly in South America, NCC dementia is misdiagnosed as Alzheimer's (Travares, 1993). Psychiatrists seldom consider it in the differential diagnosis, in spite of NCC being quite common among psychiatric patients in endemic areas. We recommend that NCC be regularly included in the differential diagnosis of psychiatric disorders in such areas and in migrants and travellers.

Dixon, H. B. F. \& LiPscomb, F. M. (1961) Cysticercosis: an analysis and follow-up of 450 cases. Medical Research Council Special Report Series, 288, 1-58.

GrIEsINGER, W. (1862) Cysticerken und ihre diagnose. Archiv der Heilkunde, 3, 399-417.

Johnstone, E. C., Macmllan, J. F. \& Crow, T. J. (1987) The occurrence of organic disease of possible or probable aetiological significance in a population of 286 cases of first episode schizophrenia. Psychological Medicine, 17, 371-379.

Richards, F. O. JR, SChantz, P. M., Ruiz-Tiben, E., et al (1985) Cysticercosis in Los Angeles County. Journal of the American Medical Association, 254, 3444-3448.

SOtrlo, J., GuERrero, V. \& RUBIO, F. (1985) Neurocysticercosis: a new classification based on active and inactive forms. A study of 753 cases. Archives of Internal Medicine, 145, 442-445.

TAVARES, A. R. JR (1993) Neurocysticercosis in the elderly. Journal of the American Geriatrics Society (in press).

Almir R. TAVARES, JR

Department of Psychiatry and Neurology

Federal University of Minas Gerais School of Medicine

Av Alfredo Balena, 190

30130, Belo Horizonte, Brazil

\section{Increased neuronal excitability in panic disorder}

SIR: Panic disorder, in spite of the marked autonomic overactivity, has been of surprisingly little interest to neurologists. To examine whether the pathophysiological mechanism in panic disorder is related to increased neuronal excitability, we examined 14 patients (10, women, 4 men; average age 34 years) who met the DSM-III-R criteria for panic disorder without agoraphobia, and compared them with an age-matched control group (11 women, 3 men).

On pathognomonic electromyographic examination, tetany in the form of typical repetitive activity during hyperventilation $(P<0.002)$, as well as a finding of the increased nerve excitability (Chvostek's phenomenon) $(P<0.001)$, was more common in patients with panic disorder. No changes in the serum electrolytes (calcium, magnesium, phosphorus, potassium) were found in either group. 
The close relationship between panic disorder and hyperventilation syndrome (overlapping with hyperventilation tetany) is well known but relatively obscure (Cowley \& Roy-Byrne, 1987). Dyspnoea, shortness of breath, dizziness, trembling or shaking, paraesthesias, discomfort, along with apprehension or fear, nervousness, irritability are common to both affections.

Hyperventilation tetany is a consequence of alkalosis, yet a similar picture of tetany may develop in mild imbalance of magnesium or calcium. The locus coeruleus and potential alterations of the respiratory centres are involved in the pathophysiology of panic attacks or hyperventilation syndrome on the one hand, and a dysfunction of the mesodiencephalic part of the reticular formation causes pathognomonic carpopedal spasms in tetany on the other hand (Nevšimal \& Roth, 1963; Hardonk \& Beumer, 1979). We believe central nervous dysfunction participates in hyperventilation tetany (Kukumberg, 1991).

The present findings provide evidence for sustained increased neuronal excitability in panic disorder, and support the involvement of the limbic system and cortex in the genesis of panic disorder, according to the neuroanatomical hypothesis (Gorman et al, 1989).

\section{A HUNDRED YEARS AGO}

\section{The treatment of neurasthenia}

Dr Constantin Paul contributes a lengthy paper on this subject to the "Bulletin Général de Thérapeutique," September and October numbers, 1893. His method of treatment is by hypodermic injection of an extract of the grey matter of the brain of the sheep. He bases his conclusions on a record of 53 cases, and upon an experience of this method of treatment of two years' duration. Nothing on the face of it seems more unlikely than that exhaustion of the body which seems more directly to depend upon an exhaustion of the central nervous system should be overcome by the use of an extract of the nervous tissues of an animal, but since the establishment of the use of the thyroid extract in the treatment of myxodema, the mouth of the sceptic is stopped observation alone is in place, and to that we must turn.

Dr Constantin Paul regards the organic liquid of the injection as a nervine tonic par excellence. Its first gift bestowed is a little sleep, which is chiefly characterized by its refreshing powers. The appetite is next awakened and the powers of assimilation. Prominent are its effect in strengthening the heart's action.
COWLEY, S. D. \& RoY-BYRNe, P. P. (1987) Hyperventilation and panic disorder. American Journal of Medicine, 83, 929-937.

Gorman, M. J., LiEbowitz, R. M., Fyer, J. S., et al (1989) A neuroanatomical hypothesis for panic disorder. American Journal of Psychiatry, 146, 148-161.

HARDONK, J. H. \& Beumer, M. H. (1979) Hyperventilation syndrome. In Handbook of Clinical Neurology, Vol. 38, pp. 309-360. Amsterdam: North-Holland Publishing Company.

KUKUMBERG, P. (1991) Side-specific electromyographic differences in tetany. Lancet, 337, 1607.

Nevsimal, O. \& Roth, B. (1963) Tetanie und Zentralnervensystem. Berlin: VEB Verlag Volk und Gesundheit.

P. KUKUMBERG A. STREČKO

Department of Neurology

Dérer's Hospital

Limbová 5

83305 Bratislava

Slovakia

\section{CORRIGENDA}

Journal, September 1993, 163 (suppl. 21), 46-54. The citation May (1990) should read Maj (1990).

Journal, September 1993, 163, 415-416. The letter "Epidemiology of vascular dementia" was also written by Elizabeth Tym (Hinchingbrooke Hospital, Huntingdon) and Secundino López-Pousa (Hospital Sta, Caterina, Girona, Spain).

In the "Bulletin Général de Thérapeutique" for September 15th, M. de Fleury records 21 cases of neurasthenia in which he employed a complex therapy, including the hypodermic use of concentrated artificial serum, the effects of which are, he says, quite as marked as those obtained from the testicular and nervous juices. The neurasthenic dyspepsia he treats on dietetic and medicinal lines; the loss of sleep by a careful regulation of the day's routine; the pains and hyperaesthesias, etc., by statical electricity and dry rubbing. Rest, which he recognizes as excellent at the start, he replaces soon by regulated labour.

These statements are rather hard upon the grey matter of the brain, but we shall perhaps have to ask ourselves concerning this new treatment how much we must put down to the needle-thrust itself with the injection of some kind of liquid and how much to the actual quality of the liquid. That treatment by injection will have a much more potent suggestive action than treatment by milder methods is self-evident.

\section{Reference}

Journal of Mental Sciences, January 1894, 134-135.

Researched by Henry Rollin, Emeritus Consultant Psychiatrist, Horton Hospital, Epsom, Surrey 